В зависимости от доступности данных и появления новых способов анализа районных территорий индикаторы могут быть изменены, а их количество увеличено.

Данная работа обобщает создание инструментария для использования в структурах территориального управления. Впервые описанная методика была использована в процессе сравнения уровней информатизации государственных структур в административных центрах субьектов Российской Федерации и показала высокую эффективность применения [4]. Было эмпирически подтверждено, что результаты предоставляют ценную информацию для экспертов в области муниципального управления как базу для сравнения и выявлений направлений, в которых растут предпочтения жителей. Основываясь на учете мнения жителей о качестве жизни в районе, методика позволяет оценивать достижение целей на разных этапах и уровнях выполнения программ: сумма индексов указывает разрыв между районами, рейтинг - порядок убывания уровней, а линейка индексов по отраслям и сравнение со средними значениями дает возможность высветить основные проблемы анализируемых территориальных единиц.

\section{ЛИТЕРАТУРА}

1. Залешина М.В. Информационные технологии в градостроительстве: вчера, сегодня, завтра // Территория и планирование, №3(33). C.106-111

2. Kusek J.,Khatouri M. Results-based Monitoring and Evaluation in Bank projects, HD Learning Week, November 6, 2006.

3. Постановление Правительства Москвы от 26 октября 2018 г. № 1310-ПП «Об утверждении Порядка осуществления мониторинга реализации Генерального плана города Москвы».

4. Жукова Т.И. Информатизация госсектора в регионах России: методика эмпирического анализа. Труды Института системного анализа РАН, 2013 г., т.62, №4

УДК 316.442

ОЦЕНКА НАСЕЛЕНИЕМ УРОВНЯ БЛАГОСОСТОЯНИЯ: СРАВНИТЕЛЬНЫЙ АНАЛИЗ В ПОСЕЛЕНЧЕСКОМ АСПЕКТЕ

DOI: $\underline{10.31618 / \mathrm{ESU} .2413-9335.2019 .6 .69 .512}$

Карпикова Ирина Серафимовна кандидат экономических наук, доцент кафедры соцчиологии и психологии, Байкальского государственного университета, г. Иркутск

\title{
POPULATION ASSESSMENT OF WELL-BEING: COMPARATIVE ANALYSIS IN THE SETTLEMENT ASPECT
}

Karpikova Irina Serafimovna

Baikal State University, Irkutsk

\section{АННОТАЦИЯ}

В работе представлены некоторые результаты исследования уровня материального благосостояния населения, проживающего в крупных, малых городах и сельских населенных пунктах Иркутской области. Анализ результатов позволил автору сделать выводы о значительных и неоднозначных трансформациях уровня и образа жизни сельского населения. Также среди всех типов населенных пунктов в аспекте формирования благосостояния и позитивного социального самочувствия населения наименее благоприятные условия предоставляют малые города.

\section{ABSTRACT}

The paper presents some results of the study of the level of material well-being of the population living in large, small cities and rural localities of the Irkutsk region. The analysis of the results allowed the author to draw conclusions about significant and ambiguous transformations of the level and lifestyle of the rural population. Among all types of settlements in terms of the formation of well-being and positive social well-being of the population, the least favorable conditions are provided by small towns.

Ключевые слова: благосостояние, доходы населения, крупный город, малый город, сельский населенный пункт.

Keywords: well-being, income of the population, large city, small city, rural locality.

Введение. Изучение уровня и качества жизни, в том числе уровня материального благосостояния населения в современной российской исследовательской практике распространено достаточно широко, в том числе в поселенческом аспекте. Однако анализ исследовательских работ по данной тематике показывает, что в большинстве случаев показатели уровня благосостояния и качества жизни, в том числе социального самочувствия населения рассматриваются на примере поселений одного типа, к которым можно отнести крупные и средние города [8], малые города [5], сельские населенные пункты [1]. Достаточно распространен сравнительный анализ 
характеристик благосостояния и качества жизни городского и сельского населения [2; 4], однако в данном контексте разделение населения на сельское и городское в большей степени рассматривается как некая обобщенная характеристика образа жизни без учета различий городского населения в зависимости от типа населенных пунктов, в которых оно проживает.

Сравнительный анализ различных характеристик и показателей, описывающих уровень и качество жизни, поведенческие стратегии населения в зависимости от типа населенного пункта как в городах, так и в сельской местности, встречается в качестве предмета и метода исследований [7], но, как правило, в конкретном контексте, например, в ситуации влияния экономического кризиса на формирование указанных характеристик.

В то же время исследования характеристик благосостояния, жизненных стратегий и социального самочувствия населения с точки зрения выявления поселенческих особенностей позволяют отслеживать складывающиеся тенденции в условиях жизнедеятельности людей, проживающих в населенных пунктов разных типов.

\section{Методы исследования и результаты.}

Исследование характеристик благосостояния, оцениваемых населением, проживающим в населенных пунктах разного типа, было проведено в 2018 г. как часть более крупного исследования в рамках проекта РФФИ под руководством автора, посвященного изучению практик социального иждивенчества в современной России. Одним из этапов данного исследования стало проведение массового опроса населения методом анкетирования.

Объектом анкетного опроса стало население одного из российских регионов - Иркутской области. Генеральную совокупность исследования составило дееспособное население региона, проживающее в отдельных муниципальных образованиях. Для определения характеристик выборочной совокупности использовались данные о населении территориального органа Федеральной службы государственной статистики по Иркутской области. Общий объем выборки составил 1200 чел. Объем и состав выборочной совокупности исследования рассчитывался с учетом фактического распределения населения региона по муниципальным образованиям согласно данным официальной статистики. Метод формирования выборки - двухступенчатый квотный отбор.

Квотирование первой ступени осуществлялось на основе отбора населения, проживающего в городской и сельской местности. В качестве муниципальных образований, население которых подлежало опросу, были выбраны:

- крупные и большие города (Иркутск, Ангарск, Братск);

- малые города (Нижнеудинск, Свирск, Тулун, Усть-Кут, Шелехов);

- сельские районы (Баяндаевский, Заларинский, Осинский, Эхирит-Булагатский).
Учитывая территориальную протяженность Иркутской области и ее зонирование в зависимости от природно-климатических и социальноэкономических условий проживания населения, в состав выборочной совокупности вошли представители населения, проживающего на всех зонируемых территориях - южной, западной и северной.

Вторая ступень квотного отбора, осуществляемого на уровне каждого отобранного для проведения опроса муниципального образования, включала в себя следующие процедуры формирования выборки:

1) определение объема генеральной совокупности (из общего состава населения были исключены лица в возрасте до 18 лет);

2) расчет объема выборочной совокупности с допущением $5 \%$ ошибки репрезентативности при доверительной вероятности $95 \%$;

3) определение квот респондентов по полу и возрасту на основе данных о половозрастной структуре населения муниципального образования.

В итоге полученная структура респондентов по квотируемым признакам в целом соответствовала демографическим характеристикам населения региона [3, с. 37]. Среди опрошенных женщины составили 57,5\%, мужчины - 42,5\%. Распределение респондентов по возрасту выглядит следующим образом: до 30 лет $21,6 \%$ опрошенных, от 30 до 50 лет - 38,6\%, старше 50 лет - 39,8\% [6, с. 58-60]. Доля респондентов, проживающих в городах, составила 78\% (в том числе в крупных и малых городах - 58\% и 20\%, соответственно), а в сельской местности $-22 \%$.

Изучение основного вопроса исследования, а именно - оценки масштабов распространенности иждивенческих проявлений в региональном социуме и отношения граждан к существованию социального иждивенчества и паразитизма, потребовало получения информации об условиях жизнедеятельности населения, которые могут способствовать формированию иждивенческих стратегий, либо противодействовать им. Поэтому содержание опросника включало в себя также вопросы, касающиеся уровня и качества жизни респондентов и их семей. Рассматривались структура доходов в зависимости от источников их получения, набор социальных проблем, характеризующих жизнедеятельность населения, а также выяснялись возможные стратегии респондентов в направлении повышения материального благосостояния их семей. Данная информация имеет самостоятельную исследовательскую ценность и в данной работе рассмотрена нами в поселенческом аспекте.

Самооценка респондентами материального положения своей семьи (табл. 1) показывает, что наиболее высокие оценки характерны для жителей села, хоть и с незначительным отрывом. Так по первым двум пунктам, указывающим на семьи с высоким уровнем благосостояния, сумма ответов сельских жителей составила $31,2 \%$ от общего количества респондентов, жителей крупных и 
малых городов - 22,8\% и 28,2\%, соответственно. Одним из объяснений данной ситуации можно считать уровень потребностей, который у жителей крупных городов выше, чем в других типах населенных пунктов. Тем не менее, полученные показатели опровергают сложившийся стереотип о заведомо более низком уровне материального благосостояния сельских жителей по сравнению с городскими.

Распределение ответов на вопрос:

«Какая из приведенных ниже оценок наиболее точно характеризует материальное положение Вашей семьи?», в \%

\begin{tabular}{|c|c|c|c|c|}
\hline \multirow[b]{2}{*}{ Варианты ответов } & \multirow{2}{*}{$\begin{array}{c}\text { В целом } \\
\text { по всем } \\
\text { респондентам } \\
\end{array}$} & \multicolumn{3}{|c|}{ В том числе среди респондентов: } \\
\hline & & $\begin{array}{l}\text { в крупных } \\
\text { городах }\end{array}$ & $\begin{array}{l}\text { в малых } \\
\text { городах }\end{array}$ & $\begin{array}{l}\text { в сельской } \\
\text { местности }\end{array}$ \\
\hline $\begin{array}{c}\text { Денег вполне достаточно, чтобы покупать } \\
\text { дорогие вещи и вообще ни в чем себе не } \\
\text { отказывать }\end{array}$ & 3,7 & 3,0 & 3,4 & 5,7 \\
\hline $\begin{array}{c}\text { Денег достаточно, чтобы часто приобретать } \\
\text { нужные товары длительного пользования и } \\
\text { высококачественные продукты питания }\end{array}$ & 22,0 & 19,8 & 24,8 & 25,5 \\
\hline $\begin{array}{c}\text { Денег достаточно для приобретения } \\
\text { необходимых продуктов питания и одежды, } \\
\text { более крупные покупки приходится } \\
\text { откладывать }\end{array}$ & 53,1 & 55,7 & 50,0 & 49,0 \\
\hline $\begin{array}{c}\text { Денег сейчас хватает лишь на покупку } \\
\text { продуктов питания }\end{array}$ & 15,1 & 15,0 & 15,6 & 15,1 \\
\hline $\begin{array}{c}\text { Денег не хватает даже на приобретение } \\
\text { продуктов питания, постоянно приходится } \\
\text { «залезать в долги» } \\
\end{array}$ & 3,0 & 3,4 & 1,7 & 3,0 \\
\hline Затрудняюсь ответить & 3,1 & 3,1 & 5,1 & 1,1 \\
\hline Всего & 100,0 & 100,0 & 100,0 & 100,0 \\
\hline
\end{tabular}

Кроме того, данные таблицы 1 указывают на то, что процентное соотношение наиболее нуждающихся семей по сумме респондентов, указавших два заключительных варианта ответа, по типам населенных пунктов практически не отличается.

Оценка респондентами благосостояния семьи в динамике (табл. 2) также указывает на наиболее позитивные изменения, прежде всего, у сельских жителей, среди которых самая высокая доля респондентов, отметивших повышение уровня доходов за предшествующий год. Негативная динамика доходов (их незначительное или значительное понижение) отмечается, в первую очередь, населением крупных городов.

Распределение ответов на вопрос:

Таблица 2

«С Вашей точки зрения, уровень жизни и доходов Вашей семьи за последние 12 месяцев», в \%

\begin{tabular}{|c|c|c|c|c|}
\hline \multirow{2}{*}{ Варианты ответов } & \multirow{2}{*}{\begin{tabular}{c} 
В целом \\
по всем \\
\cline { 3 - 5 }
\end{tabular}} & \multicolumn{3}{|c|}{ В том числе среди респондентов: } \\
\cline { 3 - 5 } & $\begin{array}{c}\text { в крупных } \\
\text { городах }\end{array}$ & $\begin{array}{c}\text { в малых } \\
\text { городах }\end{array}$ & $\begin{array}{c}\text { в сельской } \\
\text { местности }\end{array}$ \\
\hline Значительно повысились & 5,3 & 5,0 & 4,3 & 7,2 \\
\hline Несколько повысились & 21,5 & 19,5 & 19,7 & 28,5 \\
\hline Остались прежними & 44,0 & 41,9 & 48,7 & 45,2 \\
\hline Несколько понизились & 17,8 & 20,5 & 16,7 & 11,8 \\
\hline Значительно понизились & 6,2 & 8,3 & 2,6 & 3,8 \\
\hline Затрудняюсь ответить & 5,2 & 4,8 & 8,1 & 3,4 \\
\hline Всего & 100,0 & 100,0 & 100,0 & 100,0 \\
\hline
\end{tabular}

С точки зрения оценки уровня материального благосостояния населения весьма показательными являются ответы на вопрос о наличии сбережений и направлениях их дальнейшего использования (табл. 3). Респонденту разрешалось выбрать несколько вариантов ответов на данный вопрос, поэтому сумма ответов составляет более $100 \%$.

Указание целей, на достижение которых опрошенные откладывают деньги, отражают специфику приоритетов и поведенческих установок населения, определяемую, в том числе, типом населенного пункта, в котором проживают респонденты. Анализ данных таблицы 3 отражает как наличие относительно равнозначимых целей накопления в поселенческом аспекте (например, покупка автомобиля, квартиры/дачи, дорогостоящих предметов домашнего обихода, ремонт квартиры и др.), так и специфичные предпочтения населения. Например, накопления на отпуск более характерны для жителей крупных 
городов, также среди них больше всего тех, кто создает резерв на непредвиденный случай. Сельское население в числе приоритетов для сбережений называет лечение, получение образования, а также помощь детям (последняя из указанных позиций - c большим отрывом от респондентов, проживающих в малых и крупных городах).

Таблица 3

Распределение ответов на вопрос:

«Если в Вашей семье есть сбережения, то для каких целей откладываются деньги?», в \%

\begin{tabular}{|c|c|c|c|}
\hline \multirow{2}{*}{ Варианты ответов } & \multicolumn{3}{|c|}{ Среди респондентов: } \\
\cline { 2 - 4 } & $\begin{array}{c}\text { в крупных } \\
\text { городах }\end{array}$ & $\begin{array}{c}\text { в малых } \\
\text { городах }\end{array}$ & $\begin{array}{c}\text { в сельской } \\
\text { местности }\end{array}$ \\
\hline Сбережений не имеем & 31,1 & 36,9 & 32,1 \\
\hline Покупка автомобиля & 10,7 & 6,0 & 11,5 \\
\hline Покупка квартиры, дачи & 11,6 & 12,9 & 13,4 \\
\hline Покупка дорогих вещей (одежды, предметов домашнего & 7,7 & 5,6 & 5,7 \\
\hline обихода) & 13,3 & 15,5 & 16,8 \\
\hline Ремонт квартиры & 16,3 & 13,3 & 10,3 \\
\hline Отпуск, туристические поездки & 10,4 & 8,2 & 14,1 \\
\hline Лечение & 7,7 & 9,9 & 11,8 \\
\hline Получение образования & 7,9 & 4,7 & 16,0 \\
\hline Резерв на непредвиденный случай, на «черный день» & 21,7 & 2,1 & 2,7 \\
\hline Откладываем, так как не на что истратить & 2,3 & 15,5 & 12,2 \\
\hline Для другого & 1,6 & 0,9 & 1,3 \\
\hline
\end{tabular}

Для респондентов, проживающих в малых городах, по большинству названных целей накопления характерно промежуточное положение между жителями крупных городов и сельской местности. Отметим, что они не являются лидерами ни по одной из позиций сбережения, а самые низкие показатели среди респондентов, проживающих в малых городах, наблюдаются по таким целям накопления, как покупка автомобиля, лечение, помощь детям. При этом среди жителей малых городов самая высокая доля тех, кто вообще не имеет сбережений, относительно селян и проживающих в крупных городах.

Весьма интересные результаты были получены при изучении роли личного подсобного хозяйства в обеспечении благосостояния семей респондентов (табл. 4). Выяснилось, что среди сельских жителей самая высокая доля тех, кто не имеет личного подсобного хозяйства, тогда как наиболее низкие показатели по данному варианту ответа среди проживающих в малых городах. Кроме того, малые города лидируют по количеству указавших, что личное подсобное хозяйство является для них основным и дополнительным источником питания, тогда как для сельского населения данный источник получения продуктов питания имеет даже меньшую значимость, чем для жителей крупных городов, хотя с позиции основного и дополнительного источника денежных доходов личное подсобное хозяйство для жителей села остается весьма более значимым, чем для горожан.

Таблица 4

Распределение ответов на вопрос:

«Какое значение имеет личное подсобное хозяйство для бюджета Вашей семьи?», в \%

\begin{tabular}{|c|c|c|c|c|}
\hline \multirow[b]{2}{*}{ Варианты ответов } & \multirow{2}{*}{$\begin{array}{c}\text { В целом } \\
\text { по всем } \\
\text { респондентам }\end{array}$} & \multicolumn{3}{|c|}{ В том числе среди респондентов: } \\
\hline & & $\begin{array}{l}\text { в крупных } \\
\text { городах }\end{array}$ & $\begin{array}{l}\text { в малых } \\
\text { городах }\end{array}$ & $\begin{array}{l}\text { в сельской } \\
\text { местности }\end{array}$ \\
\hline Нет личного подсобного хозяйства & 46,8 & 48,6 & 38,9 & 48,9 \\
\hline Основной источник питания & 11,4 & 10,1 & 16,9 & 9,5 \\
\hline Дополнительный источник питания & 31,5 & 30,8 & 34,9 & 30,3 \\
\hline Основной источник денежных доходов & 1,4 & 1,3 & 0,4 & 2,7 \\
\hline $\begin{array}{c}\text { Дополнительный источник денежных } \\
\text { доходов }\end{array}$ & 2,5 & 2,4 & 1,7 & 3,8 \\
\hline Затрудняюсь ответить & 6,4 & 6,8 & 7,1 & 4,9 \\
\hline Всего & 100,0 & 100,0 & 100,0 & 100,0 \\
\hline
\end{tabular}

По уровню общей удовлетворенности доходами и благосостоянием своей семьи (табл. 5) вновь лидирует население, проживающее в сельской местности. Наиболее высок уровень неудовлетворенности своим материальным положением среди жителей малых городов. 
Распределение ответов на вопрос:

«Удовлетворяет ли Вас в целом уровень доходов и благосостояния Вашей семьи?», в \%

\begin{tabular}{|c|c|c|c|c|}
\hline \multirow[b]{2}{*}{ Варианты ответов } & \multirow{2}{*}{$\begin{array}{c}\text { В целом } \\
\text { по всем } \\
\text { респондентам } \\
\end{array}$} & \multicolumn{3}{|c|}{ В том числе среди респондентов: } \\
\hline & & $\begin{array}{c}\text { в крупных } \\
\text { городах }\end{array}$ & $\begin{array}{l}\text { в малых } \\
\text { городах }\end{array}$ & $\begin{array}{l}\text { в сельской } \\
\text { местности }\end{array}$ \\
\hline Вполне устраивает & 10,3 & 9,7 & 9,4 & 12,9 \\
\hline По большей части устраивает & 16,9 & 16,5 & 12,0 & 22,3 \\
\hline Отчасти устраивает, отчасти нет & 31,5 & 30,5 & 33,8 & 32,2 \\
\hline По большей части не устраивает & 22,7 & 23,4 & 28,6 & 15,5 \\
\hline Совершенно не устраивает & 14,2 & 16,1 & 8,1 & 14,4 \\
\hline Затрудняюсь ответить & 4,4 & 3,8 & 8,1 & 2,7 \\
\hline Всего & 100,0 & 100,0 & 100,0 & 100,0 \\
\hline
\end{tabular}

Заключение. Рассмотренный нами в работе вопрос, несомненно, представляет интерес и имеет исследовательскую перспективу, о чем свидетельствуют полученные данные. Высокий уровень оценок собственного благосостояния, снижение значимости традиционных источников дохода, приоритеты потребления, продемонстрированные сельскими жителями, свидетельствуют о серьезных трансформациях образа и уровня жизни сельского населения. В то же время по ряду позиций четко прослеживаются стагнирующие элементы уровня жизни и благосостояния населения, проживающего в малых городах, что подтверждает неоднократно высказываемую исследователями позицию о малых городах как зонах и сегментах ухудшающегося социально-экономического положения и самочувствия населения.

Сказанное обосновывает необходимость дальнейших сравнительных исследований представленного вопроса, в том числе мониторингового характера и на основе совместного использования количественного и качественного инструментария.

\section{Список литературы}

1. Бондаренко Л.В. Материальное положение сельских семей: статистика и самооценка // Агропродовольственная политика России. 2017. № 11(71). С. 13-16.

2. Дмитриева Ю.Н. Социальноэкономические показатели образа жизни городской и сельской молодежи и их влияние на экономическую самоидентификацию (на примере Иркутской области) // Теория и практика общественного развития. 2014. № 18. С. 92-94.

3. Карпикова И.С., Нефедьева Е.И. Феномен социального иждивенчества в оценках населения (на примере Иркутской области) // Теория и практика общественного развития. 2018. № 11(129). C. 36-41.

4. Лаврова А.П. Особенности дифференциации доходов сельского и городского населения России // Известия международной академии аграрного образования. 2016. № 27. С. 7781.

5. Лучшева В.В., Кашенкова О.В. Оценки качества жизни и уровня удовлетворенностью жизнью // Управление экономическими системами: электронный научный журнал. - 2018. - № 3. - С. 21.

6. Практики социального иждивенчества в современной России (опыт и результаты регионального исследования): коллект. моногр. / под общ. и науч. ред. И.С. Карпиковой. - М.: БИБЛИО-ГЛОБУС, 2018. - 204 с.

7. Трофимова И.Н. Динамика социальноэкономического положения россиян в условиях кризиса 2014-2015 гг.: поселенческий фактор // Политика и общество. 2015. № 6(126). С. 702-708.

$$
\text { 8. Ягафарова Д.Г. Материальная }
$$
обеспеченность городского населения региона России: основные тенденции в меняющихся экономических условиях // Современное общество: вопросы теории, методологии, методы социальных исследований. 2016. Т. 1. С. 306-313. 